\title{
Na sala de edição: “Mãe judia, 1964", de Moacyr Scliar
}

Nicola Gavioli ${ }^{1}$

Vozes do golpe é o título de um projeto editorial realizado pela Companhia das Letras em 2004 em ocasião dos quarenta anos do golpe militar no Brasil, e constituído por quatro textos tematicamente interligados, publicados em pequenos volumes individuais (A revolução dos caranguejos, de Carlos Heitor Cony; Um voluntário da pátria, de Zuenir Ventura; "Mãe judia, 1964", de Moacyr Scliar; e "A mancha”, de Luis Fernando Veríssimo). As contribuições de Cony e Ventura, breves relatos memorialísticos em que episódios anedóticos são inseridos na moldura da narrativa do golpe e de suas imediatas consequências, não dissimulam perplexidades e interrogações acerca da efetiva capacidade da testemunha de descrever e compreender o evento: "A memória, a nossa e a alheia, é, como se diz, traiçoeira" - escreve Ventura no prólogo "Mas é também inventiva: não só omite como acrescenta. O que houver de falta ou de sobra neste relato pode-se atribuir a ela" (Ventura, 2004, p. 7, grifo no original). A memória é apresentada como um processo dinâmico que nos acontece e de que somos ao mesmo tempo autores. Cony conclui seu texto com a frase: "Não consegui descrever o ano de 1964 em seus contornos históricos. Limitei-me a pensar como o assombrado japonês da anedota de Hiroshima: abri uma torneira. E ainda não tive condições objetivas para compreender o que aconteceu comigo e com os outros" (Cony, 2004, p. 84). Dominar os "contornos históricos" e as "condições objetivas" seria decisivo para a compreensão do golpe. Zuenir e Cony identificam os limites internos e externos que minam a possibilidade de uma reconstrução completa do evento.

À diferença dos relatos de Cony e Ventura, identificados como "Memórias", os livros de Scliar e Veríssimo são indicados nas capas como pertencentes ao gênero "Conto". A vontade de distinguir nas capas os nomes dos respectivos gêneros revela a incerteza dos organizadores do projeto acerca da capacidade intrínseca desses textos

\footnotetext{
${ }^{1}$ Doutor em literatura luso-brasileira e professor de português na Florida International University, Miami, Florida, Estados Unidos. E-mail: ngavioli@ fiu.edu
} 
de se revelarem aos leitores como obras memorialísticas ou literárias, aspecto interessante que sublinha a hibridez e porosidade entre essas duas tipologias textuais. Todavia, com "A mancha" e "Mãe judia, 1964" entramos distintamente no âmbito da literatura: faltam nessas narrativas considerações explícitas sobre o funcionamento e os desafios do processo mnemônico (mostradas em lugar de serem explicadas); são colocadas questões de natureza epistemológica, mas obliquamente; valorizam-se a ambiguidade e a pluralidade das vozes; exige-se do leitor uma participação ativa no ato de interpretação. Aquilo que Scliar e Veríssimo acrescentam à coletânea Vozes do golpe é uma maior inquietação em responder a perguntas como: qual é o lugar e a função das memórias traumáticas da ditadura no Brasil contemporâneo? O que fazer desse passado? Como representar ideologias antagônicas se confrontando no plano da preservação ou esquecimento da história recente? ("A mancha"); como reconhecer e como pensar, com os instrumentos da literatura, o obstinado, imaterial e sub-reptício trabalho de manipulação retórica da memória traumática das vítimas ou minorias? ("Mãe judia, 1964").

Veríssimo explora o tema do regresso do trauma através da história de Rogério, empresário de sucesso que acredita reconhecer um dia, através da mancha num carpete no corredor de um prédio abandonado, o lugar em que, anos atrás, fora vítima de tortura. Rogério se encontra numa espécie de segundo ato da vida dele: casado e dono de uma fortuna, parece ter esquecido a violência de que foi vítima, embora seus dias sejam ritmados pela ansiedade ("Era um homem organizado, apesar da agitação constante", Veríssimo, 2004, p. 10). O conto tem como foco a interação entre vítimas e carnífices no Brasil contemporâneo, onde é possível descobrir, no seio da própria família, participantes em práticas cruéis contra os direitos humanos nos anos de chumbo. Rogério quer saber mais, investigar responsabilidades e encontrar respostas: quem participou ou favoreceu práticas de tortura? Talvez o sogro tenha sido colaborador da ditadura. O desfecho do conto, ácido e inquietante, mostra a força destrutiva do silêncio e da hipócrita aceitação do inaceitável ("O lugar da quietude do seu sangue seria o esquecimento, embaixo da terra num bairro de surdos, quanto mais no fundo melhor", Veríssimo, 2004, p. 68) em nome de uma tóxica paz familiar que continuará, pelo contrário, a corroer as relações entre parentes e cidadãos. A violência da performance do convívio entre torturados e torturadores, e suas consequências a longo 
prazo, é um tema forte na produção de Veríssimo, como já mostrou Jaime Ginzburg em sua análise do conto "O Condomínio": "O apagamento da memória coletiva das referências à tortura, bem como sua banalização, potencialmente reforçam as chances de naturalizá-la e ignorar a intensidade de seu impacto. O esquecimento é, nesse sentido, em si, uma catástrofe coletiva" (Ginzburg, 2012a, p. 490-491). O perigo da banalização de experiências extremas é, como veremos, uma preocupação que atravessa o conto de Moacyr Scliar "Mãe judia, 1964", de maneira talvez mais paradoxal, tratando-se de um texto que coloca (aparentemente) em primeiro plano a voz de uma testemunha dos eventos históricos não convencional: uma paciente psiquiátrica. Como veremos, se trata de um texto concebido com o propósito de mostrar e denunciar como funciona o dispositivo de produção de silêncio ainda atuante no Brasil contemporâneo. Como "A mancha", esse conto faz parte de um conjunto de obras literárias, artísticas e cinematográficas recentes guiadas por uma preocupação ou teor testemunhal, uma vontade de ir além do testemunho "na sua modalidade de denúncia e reportagem" (Seligmann-Silva, 2003, p. 9), característico de numerosas obras da literatura do testimonio hispano-americana, em que "resta ainda uma forte influência da tradição de gêneros 'clássicos' da representação, tais como a reportagem, a biografia, a hagiografia, a confissão e o testemunho bíblico" (SeligmannSilva, 2003, p. 31). O uso das categorias de testis ou superstes não é pertinente nesses contos de Scliar e Veríssimo: seus narradores e seus protagonistas pertencem integralmente ao plano da criação literária. É, porém, a ênfase colocada nos problemas inerentes ao processo mnemônico (dúvidas, falhas, desvios, interferências externas em "A mancha") e à possibilidade de dizer o trauma (pela distância entre evento catastrófico e a linguagem da vítima, mas sobretudo pelos perigos de apropriação e manipulação ideológica dessa linguagem, em "Mãe judia, 1964") o que aproxima esses contos de preocupações e obsessões fundamentais da literatura do testemunho.

II

O período da ditadura militar brasileira é representado no romance mais célebre de Moacyr Scliar, O centauro no jardim (1980), na sua dimensão claustrofóbica e paranoica de tempo do medo. Uma comunidade de burgueses morando em um espaço hermeticamente 
fechado e protegido por guardas armadas se torna o espaço simbólico da narrativa para representar uma época e uma mentalidade. $\mathrm{O}$ conto “Mãe judia, 1964" é também ambientado num lugar enclausurado e vigiado, uma instituição psiquiátrica da Porto Alegre dos primeiros anos 1960, a Clínica Renascença. O texto se articula em três seções, sem títulos, identificados do ponto de vista gráfico (alternância de caracteres itálicos e romanos), correspondentes à introdução em primeira pessoa de narrador, um jovem médico recém-formado, à fala de uma paciente psiquiátrica (a mãe judia do título) e, circularmente, à voz do médico. $\mathrm{Na}$ produção de Scliar, encontramos com frequência narrativas de aprendizagem da profissão médica (Histórias de um médico em formação, 1962; Histórias de aprendiz, 2004, entre outros). Este conto começa também como uma narrativa de Bildung médica:

1964 começou mal. Acordei tarde, naquele $1^{\circ}$ de janeiro, tarde e com uma atroz dor de cabeça. Médico recém-formado [...]. Aquele era o ano em que eu me tornaria um profissional sério [...]. Passei meses deprimido, sem saber o que fazer e tão alheado que o golpe militar nem chegou a mexer muito com minha vida. Política, em realidade, nunca me interessara muito; eu votava por obrigação e sempre ao acaso; na faculdade, era apontado como alienado pelo pessoal de esquerda e como inocente útil pelo pessoal de direita. O que não chegava a ser uma acusação; achavam que eu era assim mesmo, interessado em medicina mas desligado do mundo (Scliar, 2004, p. 7-9).

Ensimesmado e desorientado, o narrador acha emprego na Clínica Renascença, para cuidar de pacientes psiquiátricos. A diretora dessa clínica, a doutora Lucrécia, que mantém contato com políticos e grandes empresários para subir na carreira,

perguntou se eu estava envolvido com política. [...] explicou que, diante da situação do país, não queria ver nem a clínica, nem os médicos, metidos em confusão. Lembrou que, na faculdade, muitos estudantes haviam tomado posições de esquerda, o que agora se tornava perigoso (Scliar, 2004, p. 11-12).

A ambição de Lucrécia é se tornar uma psiquiatra reconhecida e celebrada em grandes congressos internacionais. Para coletar material para suas pesquisas, registra, sem pedir autorização, as falas de seus pacientes, escondendo um microfone em seu estúdio. Em particular, é uma paciente de meia-idade, judia, "que tinha sido hospitalizada por 
um surto psicótico, desencadeado pela prisão (por motivos políticos) do filho" (Scliar, 2004, p. 15-16) a se tornar objeto de seu interesse para a escrita de um artigo acadêmico sobre delírios místicos. Identificada como a "mulher da capela" pelo hábito de monologar diante de uma estátua da Virgem, repetindo "sem cessar, de forma às vezes compreensível às vezes não" (Scliar, 2004, p. 17) sua história pessoal, a voz dessa paciente é gravada por um microfone escondido na estátua. O narrador se torna cúmplice de Lucrécia. A gravação secreta é um ato autoritário, apresentado como prática de exceção em nome da pesquisa científica, que quebra regras de ética profissional médica, despertando também no leitor associações com outras formas de extorsão de informações praticada em interrogatórios durante a ditadura. Embora o material recolhido seja promissor, o projeto do artigo é logo abandonado: Lucrécia decide abandonar clínica e profissão para se tornar amante de um político importante do regime instaurado em 64 . O narrador, porém, não consegue deixar de pensar nas gravações da mulher da clínica:

O que fora feito delas? Liguei para a clínica, consegui o endereço de Lucrécia em Brasília e escrevi-lhe a respeito. Semanas depois, recebi dela um texto datilografado: era a transcrição das gravações. Um lacônico bilhete dizia que o material não fora aproveitado para nenhum trabalho; mesmo assim ela lhe dera uma redação coerente e até um pouco ficcional, coisa atribuível, segundo suas palavras, a uma frustrada vocação de escritora. Enviava-me o texto apenas para que dele eu tomasse conhecimento; não deveria mencioná-lo a ninguém, muito menos as circunstâncias em que fora obtido (Scliar, 2004, p. 19-20).

A parte central do conto coincide com a transcrição datilografada das gravações orais da doente da clínica. Sabemos que o discurso oral da paciente teria características capazes de despertar, segundo Lucrécia, grande interesse na comunidade científica. A fala deveria, portanto, se destacar, apresentar peculiaridades, rupturas das convenções linguísticas, ou brechas na ordem de representação do mundo (é classificada como delírio místico); ou, pelo menos, proporcionar um efeito de estranheza no ouvinte imaginário ou no leitor. Porém, a transcrição feita pela diretora apaga (programaticamente) as qualidades distintivas dessa fala.

No livro The Wounded Storyteller: Body, Illness and Ethics, publicado nos Estados Unidos em 1995 e considerado uma referência nos estudos sobre "illness narrative" e "disability studies" ("narrativa da doença" e "estudos 
sobre deficiência"), Arthur W. Frank aponta características muito frequentes na chaos narrative (narrativa do caos), um tipo de narrativa (ou antinarrativa) constituída por fragmentos e lacunas, e derivada de experiências traumáticas. Pacientes que sofreram feridas profundas no corpo e na psique (que Frank chama de "wounded storytellers", contadores de histórias feridos, magoados) tendem a produzir um discurso desprovido de uma clara sequência narrativo-temporal, "um contar sem mediação, um falar de si sem real capacidade autorreflexiva", caracterizado por "um presente incessante sem um passado memorável e sem um futuro que valha a pena antecipar" e pela "estrutura sintática 'e então e então e então' [...] palavras em staccato" (Frank, 2013, p. 98-99, tradução nossa). ${ }^{2}$

O delírio místico da protagonista do conto de Moacyr Scliar é apresentado duma forma ordenada e perfeitamente inteligível: os planos temporais são claramente definidos, o texto se organiza sem repetições obsessivas. É um texto simples, que proporciona uma leitura fluente, sem aparentes desafios para o leitor. Qual é a razão? É preciso sublinhar que a clareza é um dos traços estilístico privilegiados em toda a obra do Moacyr Scliar, autor reconhecido, sobretudo, por suas habilidades de contador de histórias em sentido clássico. ${ }^{3}$ Além disso, poderia existir uma resistência, por parte de Scliar, à repetição de abusadas técnicas modernistas (pensemos na desordem de certos monólogos em romances de William Faulkner) para representar a perturbação mental. Todavia, mais interessante para nós é interpretar as características da transcrição da fala da mãe judia como o resultado de um profundo trabalho de editing por parte da diretora da clínica, simpatizante da ditadura. Nesse monólogo, os sinais da loucura da paciente são ornamentais, episódicos, literários (é mencionada, por exemplo, a interferência de objetos inanimados, bibelots de sala de estar, que querem se comunicar com a mulher), não investem na substância

\footnotetext{
${ }^{2}$ Embora o livro de Arthur W. Frank enfoque sobretudo no discurso de pacientes emocionalmente traumatizados por feridas e doenças do corpo, o modelo de narrativa do caos tem sido adotado na bibliografia acadêmica também para descrever o discurso da algumas perturbações mentais como a depressão (ver, por exemplo, o ensaio de Brenda Dyer no volume Depression and Narrative: Telling the Dark). No caso da protagonista de "Mãe judia, 1964", permanece incerta a etiologia do sofrimento mental (causado pelo choque emocional do aprisionamento do filho ou por uma doença psíquica mais antiga exacerbada pelo trauma?).

${ }^{3}$ Num recente prefácio a crônicas de Scliar, Regina Zilberman (2013, p. 12) indica na simplicidade "uma das marcas mais notáveis" da prosa de Scliar; Nelson Vieira (2009, p. 243) define como "parábolas" o vasto conjunto da produção de Scliar.
} 
do discurso e a forma dele, sempre muito vigiada. Trata-se de um trabalho editorial radical, apresentado (e disfarçado) como "coisa atribuível, segundo suas palavras, a uma frustrada vocação de escritora" (Scliar, 2004, p. 19). As intervenções da diretora são reconhecíveis em diversos aspectos:

a) a linearidade da narrativa que contradiz características típicas da fala do delírio e da perturbação psíquica (fragmentação, confusão de planos temporais, elipses);

b) a coerência lógica do discurso (apesar das digressões); respeito das relações de causa-efeito e da norma sintática; ${ }^{4}$

c) a capacidade de pensar racionalmente a etiologia da doença mental: "Depois do parto enlouqueci. Dizem que é comum, mulheres enlouquecerem depois do parto. Não sei. O fato é que eu já era meio louca e fiquei louca por inteiro, louca varrida, louca de pedra" (p. 49);

d) o uso de figuras retóricas (o humor...) para obter determinados efeitos: "Ali estava eu, entre alicates e martelos, entre latas de tinta e pacotes de pregos. Desculpa falar em pregos; sei que teu filho foi pregado à cruz... Melhor não lembrar essas coisas, não é? Respeito tua dor. Sou louca, mas não sou grossa. Sou louca, mas não sou burra" (p. 34);

e) a descrição paródica da atividade de guerrilha: "A psicóloga disse que eu precisava mudar minha aparência. [...] Impaciente, descartou meus argumentos: tínhamos de raciocinar como Gabriel, e adotar os valores dele, inclusive em termos de vestuário [...] Calçando sandálias,

\footnotetext{
${ }^{4}$ A relação entre linguagem e eventos traumáticos (em particular as alterações da linguagem nas vítimas da tortura) foi objeto de estudo, entre outros, de Maren e Marcelo Viñar (Exílio e tortura), Hélio Pellegrino (Brasil: nunca mais) e Jaime Ginzburg (Crítica em tempos de violência). No ensaio "Memória da ditadura em Caio Fernando Abreu e Luis Fernando Veríssimo", Ginzburg enfatiza, em perspectiva adorniana, que a "opção da narrativa pelo privilégio da sintaxe coordenativa deixa elementos independentes uns com relação aos outros. É uma visão do mundo em mosaico, em caleidoscópio, que não se submete à lógica da causalidade e da sequência linear" (Ginzburg, 2012b, p. 427). O monólogo da mãe judia, pelo contrário, respeita causalidade e lógica. A parataxe de muitas frases não comunica uma falta de subordinação lógica ou de hierarquia entre as partes. O mundo, na fala da paciente, é ainda coeso e unitário.
} 
impregnados da sujeira das ruas, da sujeira popular, teus pés mostrarão identificação com as massas. E aí chegou o momento decisivo. Dona de uma nova linguagem e de uma nova imagem, eu estava preparada para invadir o território até então hostil, nele desfraldando a bandeira que caracterizaria a minha revolucionária condição de mãecompanheira" (p. 85-86);

f) a banalização da tortura, a infantilização da oposição ao governo: "Ali estava meu filho Gabriel, meu filhinho, o rosto e os braços cheios de manchas roxas e de queimaduras de cigarro, dois dentes arrancados a soco. Mas havia pelo menos um lado bom; não haviam apurado nada contra ele, não o indiciariam. Aí me dei conta: o que eles faziam na faculdade, no Alaska, na casa de um, na casa de outro, era só aquilo, só conversa. A suposta resistência que eles e muitos outros haviam montado não passava de um castelo de cartas que agora desabava" (p. 93-94);

g) a apresentação da luta contra a ditadura como capricho revolucionário corruptor das relações familiares: "Segundo o Gabriel eu não passava de uma burguesona. Isso me caracterizava como inimiga" (p. 84);

h) a defesa da aceitação passiva da ditadura: "Imaginei que a vida voltaria ao normal. Sim, havia uma ditadura, mas, e daí? Era preciso continuar vivendo. Foi o que eu disse para Gabriel: esses caras não vão ficar muito tempo, tudo o que a gente tem de fazer é esperar um pouco, uns meses, talvez um ano" (p. 94);

i) o distanciamento da classe trabalhadora: "Eu não gostava de ver meu filho na malharia, mexendo com as máquinas ou colocando suéteres nas embalagens. Em primeiro lugar porque pretendia algo melhor para ele" (p. 56); “[...] tinha uma faxineira [...] Gabriel via nela uma representante da classe trabalhadora. A faxineira, para mim uma safada, dava trela para o guri; perguntava coisas, e até queria ler os livros dele (encenação: era meio analfabeta). Conversavam horas, nas quais, evidentemente, as vidraças ficavam 
esperando para serem limpas" (p. 68-69); "Aqui conto tudo, desde que a faxineira não esteja por perto, aquela espiã. Aquela traidora. Mulher safada. Recalcada. Repara na magreza dela, essa magreza que vem da ruindade. É dessas que não comem bem, que não bebem bem" (p. 99).

Não se trata, como notamos, de uma genérica intervenção estilística, mas de uma radical reescrita da fala da paciente, ditada por uma vontade ideológica bem definida. Scliar deixa ao leitor a tarefa de entender que a coerência e a fluidez do texto correspondem à vontade de editar (e tornar inofensiva e banal) a voz do delírio e da dor. Assistimos à domesticação da violência, da tortura, de um sistema autoritário. Apaga-se a forma que é também a substância de experiências extremas. Resulta uma versão depurada do trauma, depauperada de energia e potencial de denúncia, e incapaz de suscitar fortes reações de indignação. Scliar reproduz nesse conto uma prática violenta que, sem deixar marcas em suas vítimas, tem provocado consequências graves e duradouras na sociedade brasileira: o processo de normalização e abrandamento, através das armas da persuasão, da banalização e do silêncio, de um passado recente traumático e intolerável. Dessa prática temos numerosos exemplos: afirmar, por exemplo, hoje, cinquenta anos depois do golpe de 64, que a ditadura no Brasil foi branda em comparação com a de outros países latinoamericanos, ou que a tortura foi um mal necessário, ou que a anistia foi a melhor solução para a pacificação da sociedade brasileira, significa querer enfraquecer a força dos relatos das vítimas, normalizar e justificar experiências extremas de abuso. Numa reportagem de 2012 da TV Brasil ("Crimes da ditadura", no programa Caminhos da reportagem), o general reformado Luiz Eduardo Rocha Paiva afirma para o entrevistador: "Houve tortura. Assim como houve tortura também do lado da guerrilha. Isso ninguém fala. $\mathrm{O}$ torturador e o terrorista ambos são criminosos. O que eu defendo é que houve uma anistia e portanto essa anistia tem que ser respeitada". Nesse momento, assistimos a um típico exercício de editing e banalização do passado.

Além disso, "Mãe judia, 1964" poderia ser também uma crítica de formas textuais realísticas tradicionais adotadas para representar eventos traumáticos: romances e contos que intentam descrever o horror da violência através de técnicas narrativas convencionais, por isso 
tornando familiar aquilo que deveria perturbar. ${ }^{5}$ Por isso, paradoxalmente, o gesto de Lucrécia corre o risco de ser praticado, embora não intencionalmente, até por autores que repudiam a ditadura e a violência. A terceira e última parte do conto retoma o ponto de vista do médico, decidido a deixar no passado, e possivelmente esquecer, sua experiência na clínica e o monólogo da paciente:

Resolvi esquecer. Naquela época, quanto menos se sabia, melhor. Se não sabíamos de nada, se não nos interessávamos por nada, poderíamos até viver em relativa calma. Talvez acordássemos no meio da noite pensando em certo oculto microfone. Talvez isso nos desse até insônia. Mas de insônia, convenhamos, ninguém está livre (Scliar, 2004, p. 108).

Essa conclusão se aproxima do desfecho do conto "A mancha", de Veríssimo. Em lugar da angustiado sacrifício do silêncio do protagonista de Veríssimo, que continua no convívio com o sogro colaborador da ditadura para salvar uma suposta paz familiar, minada por tensões e ameaças subterrâneas, o narrador de Scliar quer virar a página da própria vida, buscando um distanciamento dos eventos passados. Ambos os autores descrevem o gesto de performance amnésica que muitos cidadãos brasileiros quiseram adotar e mantiveram até hoje.

A atenuação da força dos relatos de vítimas de experiências traumáticas através da manipulação retórica (apresentando uma versão mais aceitável, trivial e desprovida de lacerações e efeitos permanentes da dor) é o gesto denunciado em "Mãe judia 1964". Essa operação de banalização e subtração de informações corresponde a uma ideologia que, sob o véu da pacificação da sociedade, tem como objetivo a impunidade e a perpetuação de abusos e violências. Obras de literatura como "Mãe judia, 1964" mostram como o trabalho na sala de edição do passado persiste, sutil e obstinado, mas em formas reconhecíveis e, por isso, contrastáveis.

\footnotetext{
${ }^{5}$ Como falar de experiências extremas da contemporaneidade através de recursos literários do século XIX? Em seu artigo "O narrador na literatura brasileira contemporânea", Jaime Ginzburg aborda a rica produção de textos literários com foco em eventos traumáticos e/ou caracterizados por narradores não tradicionais, sublinhando técnicas de representação de ruptura do modelo realista. A escrita fragmentária é uma dessas técnicas, embora Ginzburg não lhe atribua relevância ou significado autônomos. Ela deve ser parte de uma articulação complexa: "É importante a combinação delicada entre recursos de fragmentação, temas ligados à repressão e proposições associadas à necessidade de repensar a história" (Ginzburg, 2012c, p. 204).
} 


\section{Referências}

CONY, Carlos Heitor (2004). A revolução dos caranguejos. São Paulo: Companhia das Letras.

CRIMES da ditadura (2012). Caminhos da reportagem, Brasília: TV Brasil, 10 de outubro. Programa de TV. Disponível em: < http://goo.gl/KNLQCA >. Acesso em: 5 abr. 2014.

DYER, BRENDA (2008). Winter tales: comedy and romance story-types in narratives of depression. In: CLARK, Hilary (ed.). Depression and narrative: telling the dark. Albany: State University of New York Press.

FRANK, Arthur W. (2013[1995]). The wounded storyteller: body, illness and ethics. Chicago: University of Chicago Press.

GINZBURG, Jaime (2012a). Escritas da tortura. In: Crítica em tempos de violência. São Paulo: Edusp.

(2012b). Memória da ditadura em Caio Fernando Abreu e Luis Fernando Veríssimo. In: Crítica em tempos de violência. São Paulo: Edusp.

(2012c). O narrador na literatura brasileira contemporânea. Tintas:

Quaderni di letterature iberiche e iberoamericane, Milão, n. 2, p. 199-221.

SCLIAR, Moacyr (1980). O centauro no jardim. São Paulo: Companhia das Letras. (2004). Mãe judia, 1964. São Paulo: Companhia das Letras.

SELIGMANN-SILVA, Márcio (2003). Introdução. In: SELIGMANN-SILVA, Márcio (org.) História, memória, literatura: o testemunho na era das catástrofes. Campinas: Editora da Unicamp.

VENTURA, Zuenir (2004). Um voluntário da pátria. São Paulo: Companhia das Letras.

VERÍSSIMO, Luis Fernando (2004). A mancha. São Paulo: Companhia das Letras.

VIEIRA, Nelson (2009). Contemporary jewish writing in Brazil: an anthology. Lincoln: University of Nebraska Press.

ZILBERMAN, Regina (2013). Leitura prazerosa sobre a saúde. In: SCLIAR, Moacyr. Território da emoção: crônicas de medicina e saúde. São Paulo: Companhia das Letras.

Recebido em dezembro de 2013.

Aprovado em março de 2014. 


\section{resumo/abstract}

\section{Na sala de edição: "Mãe judia, 1964", de Moacyr Scliar}

Nicola Gavioli

Tentativas de cobrir responsabilidades dos crimes da ditadura e de alterar ou silenciar a força dos depoimentos de vítimas de violência continuam a se manifestar no Brasil contemporâneo. O propósito deste artigo é mostrar como o texto "Mãe judia, 1964", de Moacyr Scliar, ilumina, sob a aparência de conto de aprendizagem e de monólogo de uma doente mental, uma prática violenta que, sem deixar marcas em suas vítimas, teve efeitos graves e duradouros na sociedade brasileira. O processo de normalização, através das armas da persuasão, da banalização e do silêncio, de um recente passado traumático, é mostrado aos leitores como reconhecível e por isso contrastável.

Palavras-chave: Moacyr Scliar, ditadura, manipulação, encobrimento.

\section{In the editing room: "Jewish mother, 1964" by Moacyr Scliar}

\section{Nicola Gavioli}

In contemporary Brazil, efforts continue to conceal liabilities of crimes committed during the years of dictatorship and to alter or weaken the testimony of victims who have spoken out against their perpetrators. This article explores how the short story "Jewish mother, 1964" by Moacyr Scliar, under the guise of a coming-of-age story and a monologue of a mentally ill patient, sheds light on violent practices that, without leaving visible marks on the body, have incurred serious and longstanding wounds within Brazilian society. Readers are made to see how persuasion, trivialization, and silencing are complicit in the "normalizing" of recent and traumatic histories. If made recognizable, this silencing practice could directly be challenged.

Keywords: Moacyr Scliar, dictatorship, manipulation, concealment. 